
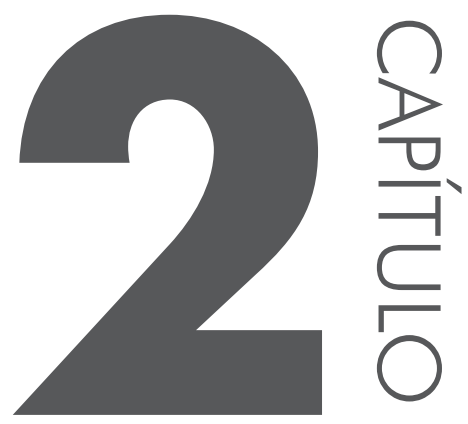

\title{
Correlação entre ordem verbo-sujeito e sujeito nulo: a trajetória da mudança no português de Santa Catarina'
}

Izete Lehmkuhl Coelho

Gésyka Mafra Silva Érica Marciano de Oliveira Zibetti

\subsection{INTRODUC̣ÃO}

Estudos formais sobre a representação do sujeito no português brasileiro (PB) apontam uma mudança no parâmetro do sujeito nulo. O PB estaria passando de uma língua de sujeito nulo [+pro-drop] para uma língua de sujeito expresso [-prodrop]. A literatura gerativista tem associado às línguas positivamente marcadas em relação ao parâmetro do sujeito nulo um conjunto de propriedades que as diferenciam das línguas negativamente marcadas em relação a esse parâmetro, a saber:

\footnotetext{
${ }^{1}$ Este trabalho parte de uma discussão preliminar apresentada na Associação Brasileira de Linguística ABRALIN/2015 por Coelho, Zibetti e Melo (cf. COELHO et al., 2015). Agradecemos à Letícia Cortellete Melo pela colaboração na coleta das ocorrências de sujeito expresso e na categorização da ordem do sujeito (SV e VS) da amostra do século XX.
} 

a. sujeito pronominal nulo;
b. inversão "livre" de sentenças simples;
c. movimento longo de qu-sujeito;
d. pronomes resumptivos vazios em orações encaixadas;
e. aparente violação do filtro *[that-t].

Em línguas como o italiano - línguas reconhecidamente de sujeito nulo -, todas essas propriedades são respeitadas ${ }^{2}$. Segundo Chomsky (1981), em línguas prototipicamente [+pro-drop], o sujeito nulo é na verdade uma forma default; o sujeito só é expresso, nesse caso, se houver uma motivação relacionada a questões de ênfase ou de contraste, ou, ainda, uma motivação relacionada à intenção de evitar a ambiguidade.

Essa associação entre ordem dos constituintes sentenciais e parâmetro prodrop (CHOMSKY, 1981; RIZZI, 1988; KATO, 2000; 2002) parece fazer sentido quando olhamos para trabalhos que analisaram o português antigo (cf. RIBEIRO, 1995; 2001; TORRES MORAIS, 1993).

Conforme aponta Torres Morais (1993), há razões para se pensar que o português antigo tenha sido uma língua de sujeito nulo com um sistema de ordem de sujeito expresso pós-verbal (VS), como o francês antigo. Esse argumento se respalda em estudos de Roberts (1993 apud TORRES MORAIS, 1993). Parece que há na história do francês um movimento conjugado de perda de VS (com verbo em segunda posição na sentença, como em XVS) e perda do sujeito nulo. $\mathrm{O}$ francês, ao perder a restrição dessa ordem XVS, segundo o autor, estaria reanalisando as declarativas como construções sujeito-verbo-objeto (SVO).

Relativamente ao português antigo, Torres Morais (1993) e Ribeiro (1995; 2001) defendem que o percurso de mudança atestado nessa língua deve ter sido muito semelhante ao do francês. É possível pensar, segundo essas autoras, que o português foi um tipo de língua XVS até o século XVII, como os exemplos de (1) a (3), retomados das autoras, ilustram. A partir de então, esses tipos de construções passaram a ser cada vez mais escassos na escrita brasileira dos séculos seguintes.

(1) Com tanta paceença sofria ELA esta enfermidade (séc. XIV)

(2) Com estas e outras taaes rrazoões arrefeçeo EL-RREI de sua brava sanha (séc. XV)

(3) E esta vertude de paceença ouve ESTE SANTO MONGE LIBERTINO mui compridamente (séc. XV)

\footnotetext{
2 Essas propriedades são exemplificadas, em uma língua como o italiano, por Kato (2002, p. 328):

a. Ho trovato il libro.

b. Há mangiato Giovanni.

c. L'uomo [che mi domando [chi abbia visto]]

d. Ecco la ragazza [che mi domando [chi crede [che possa VP]]]

e. Chi credi [che partira]?
} 
Torres Morais (1993), ao descrever as construções de inversão do sujeito em peças de teatro escritas por brasileiros em diferentes séculos, apontou, ainda, que essas construções disputavam espaço com um aumento gradativo de construções com sujeito anteposto ao verbo, como SV ou XSV (isto é, construções com verbo em segunda ou terceira posição), o que pode evidenciar, segundo a autora, que os falantes do português estariam reanalisando as declarativas XV como estruturas (X)SVO, nos mesmos moldes da mudança observada no francês.

Paralelamente a essa mudança, estudos (cf. KATO; TARALLO, 1988; KATO, 2002; KATO et al., 2006, entre outros) mostram que línguas românicas [+pro-drop] como o espanhol e o italiano permitiriam a posposição livre do sujeito, isto é, a posposição do sujeito em diferentes contextos sintáticos (com verbos transitivos diretos e indiretos, intransitivos, cópulas, inacusativos etc.). Essa possibilidade de posposição do sujeito foi atestada na escrita brasileira de sincronias passadas. $\mathrm{Na}$ variedade brasileira atual, entretanto, é bastante restrita a ordem VS, sendo aceita (mais) naturalmente com verbos monoargumentais (especialmente os inacusativos). Dessas descobertas, duas conclusões derivadas de análises empíricas muito relevantes sobre a história do PB são fundamentais para a discussão deste trabalho.

A primeira delas advém de estudos sobre a representação do sujeito pronominal no $\mathrm{PB}$, os quais evidenciam mudança, no parâmetro do sujeito, de uma língua marcada positivamente para o parâmetro [+pro-drop] até mais ou menos a década de 1930 do século XX para uma língua marcada negativamente para esse parâmetro [-pro-drop] no final do século XX (cf. DUARTE 1993; 1995; DUARTE et al., 2012; NUNES DE SOUZA et al., 2010, entre outros).

Ao mesmo tempo, atesta-se mudança de uma sintaxe que permite variação da ordem do sujeito com verbos transitivos a uma sintaxe que tem preferência por uma ordem mais rígida SVO. Há evidências de que o PB tenha perdido a propriedade de inversão livre de sentenças simples, em especial para verbos de mais de um argumento, em que se verifica a preferência pela ordem SVO. Em construções com verbos monoargumentais, principalmente verbos inacusativos, a ordem VS ainda é bastante frequente no final do século XX e aparece em geral associada à presença de condicionadores semânticos como animacidade e traços de definitude e de especificidade do sujeito (cf. BERLINCK, 1988, 1989; 1995; COELHO, 2006; COELHO; BERLINCK, 2012; BERLINCK, COELHO, no prelo).

Trabalhos que investigam esses dois fenômenos correlacionados ainda são escassos no PB. Temos notícias de estudos muito específicos, como o de Santos e Soares da Silva (2012) sobre as construções com verbos inacusativos. Os autores observam, em uma amostra de peças de teatro escritas entre 1845 e 1992, que a queda do sujeito nulo em contextos de monoargumentos se assemelha à queda 
da ordem VS de alguns verbos inacusativos, como morrer, nascer e envelhecer. Os resultados apontam para uma curva muito parecida entre o declínio do sujeito nulo - de $80 \%$ para $30 \%$ a $20 \%$ - e uma restrição acentuada da ordem VS nesse caso, de $50 \%$ na peça de 1845 a $0 \%$ na peça de 1992 . Entretanto, essa ordem se mantém na faixa de $50 \%$ em contextos com os demais verbos inacusativos.

Coelho et al. (2015) mostraram, em uma versão preliminar deste trabalho, que parece haver uma associação entre ordem VS e sujeito nulo. Para ampliar essa discussão sobre a trajetória desses dois processos de mudança, pretendemos verificar, em duas amostras de cartas pessoais catarinenses dos séculos XIX e XX pertencentes ao projeto "Para a História do Português Brasileiro de Santa Catarina" (PHPB-SC) - aqui retomadas -, qual a correlação entre as variáveis ordem do sujeito (SV e VS) e forma de representação do sujeito pronominal (nulo e expresso) em contextos de sentenças declarativas com verbos transitivos, intransitivos, cópulas e inacusativos, adotando alguns pressupostos da Teoria da Variação e Mudança (WEINREICH; LABOV; HERZOG, 1968). As amostras utilizadas pertencem ao banco diacrônico do PHPB-SC e compreendem dois momentos: (i) século XIX (1880/1890), representado por cartas do poeta Cruz e Sousa à sua amada, Gavita, e dos amigos Araújo Figueiredo e Virgílio Várzea a Cruz e Sousa; e (ii) meados do século XX (1960), representado por cartas de amor e de amizade escritas por remetentes de Santa Catarina a um jovem do Vale do Itajaí, identificado como [Destinatário N].

Vamos observar a possibilidade de dizer que a atuação de construções OVS está atrelada a um sistema de sujeito preferencialmente nulo. Os exemplos a seguir da amostra analisada neste trabalho ilustram esses dois casos.

(4) Nesse artigo vibrarás bem fundo que a mesma Gazeta, que me descompõe, reconhece plenamente o meu mérito [Carta de Virgílio Varzea a Cruz e Sousa - 28 de outubro de 1882]

(5) A noite passada gastei-a toda ao lado dellas, sobretudo d'ella, contandothe os saltos, as saudades, os desesperos e angustias que d'alli por diante ia ter $O$ MEU CORAÇÃO [Carta de Virgilio Várzea para Cruz e Sousa - 3 de Janeiro de 1889]

Partindo das evidências citadas acima de que a história do PB tem revelado dois processos paralelos de mudança sintática - a perda do sujeito nulo e a perda da ordem verbo-sujeito (VS) -, resgatamos discussões de estudos anteriores a respeito da ordem dos constituintes e da representação do sujeito pronominal, correlacionando a ordem VS aos contextos de sujeito nulo, a fim de entender melhor a história desses processos. 
Nossa hipótese é de que a trajetória de mudança de sujeito nulo para sujeito pronominal expresso acompanhe a trajetória de mudança de OVS transitiva para SVO nos dois séculos investigados: um crescente enrijecimento da ordem SVO (com baixos índices de inversão transitiva) e uma queda acentuada do sujeito nulo.

Este trabalho está assim organizado: inicialmente, apresentamos alguns resultados de estudos dentro do quadro da Teoria da Variação e Mudança, que mostram, separadamente, a trajetória de mudança dos dois fenômenos sintáticos. Em seguida, apresentamos nossos resultados sobre a correlação dos dois fenômenos sintáticos em variação e mudança na escrita catarinense dos séculos XIX e XX. Por fim, fazemos algumas considerações a respeito do percurso de mudança observado na amostra investigada.

\subsection{O PARÂMETRO DO SUJEITO NULO E A ORDEM DO SUJEITO NO PORTUGUÊS BRASILEIRO}

Nesta seção trazemos alguns resultados de trabalhos sobre o PB no âmbito da Teoria da Variação e Mudança (cf. WEINREICH; LABOV; HERZOG, 1968; LABOV, 1972) que atestam um percurso de mudança dos fenômenos variáveis ordem do sujeito (SV e VS) e representação do sujeito pronominal, com foco na ordem VS e no sujeito nulo.

\subsubsection{A ORDEM DO SUJEITO EM SENTENCCAS DECLARATIVAS}

Diversos trabalhos de Sociolinguística Variacionista sobre a ordem do sujeito têm mostrado uma tendência ao enrijecimento da ordem SVO no português falado e escrito no Brasil (LIRA, 1986; BERLINCK, 1988; 1989; 1995; COELHO, 2000; 2006; ZILLES, 2000; SPANO, 2008; SANTOS, 2008, entre outros). Berlinck $(1988$; 1989) mostra um decréscimo acentuado da frequência da ordem VS(O) ao longo dos últimos séculos no português escrito no Brasil: de $45 \%$ de VS $(\mathrm{O})$ no século XVIII, passando por $31 \%$ no século XIX, e chegando a apenas $21 \%$ no século XX. Essa queda, segundo a autora, está condicionada principalmente pela transitividade do verbo da construção sintática, como a Tabela 2.1 aponta. 


\begin{tabular}{|l|l|l|l|}
\hline Cruzamento entre século e transitividade do verbo & Século XIX \\
& $(\mathbf{1 7 5 0 )}$ & $\mathbf{( 1 8 5 0 )}$ & $\begin{array}{l}\text { Século XX } \\
\text { Amostra de Curitiba (1987) }\end{array}$ \\
\hline Verbo intransitivo existencial & $100 \%$ & $97 \%$ & $99 \%$ \\
\hline Verbo intransitivo não existencial & $59 \%$ & $47 \%$ & $46 \%$ \\
\hline Verbo de ligação (ou cópula) & $47 \%$ & $30 \%$ & $23 \%$ \\
\hline Verbo transitivo indireto & $34 \%$ & $36 \%$ & $8 \%$ \\
\hline Verbo transitivo direto & $34 \%$ & $21 \%$ & $3 \%$ \\
\hline Verbo transitivo direto e indireto (ou bitransitivo) & $30 \%$ & $15 \%$ & $0 \%$ \\
\hline Total & $\mathbf{4 5 \%}$ & $\mathbf{3 1} \%$ & $\mathbf{2 1 \%}$ \\
\hline
\end{tabular}

Tabela 2.1 - Percentuais de VS segundo o grupo de fatores "transitividade do verbo" (adaptada de Berlinck, 1988, p. $88,192,193,220)$.

O percurso diacrônico correlacionado com a transitividade do verbo evidencia um enrijecimento da ordem SVO nas construções com verbos transitivos (diretos e indiretos), com índices de inversão que vão da faixa de 20\% (no século XVIII) a zero (no século XX). Já os verbos intransitivos existenciais e não existenciais são contextos favorecedores da ordem VS ao longo do tempo. Os exemplos ${ }^{4}$ a seguir, extraídos de Berlinck (1988, p. 53-63), ilustram casos de ordem variável do sujeito em diferentes contextos sintáticos.

(6) Os padres que já me esperavam me conduziram ao carneiro em que se acha sepultado men pai e senhor donde esta uma capela, e ali lhe fez TODA A COMUNIDADE um sufrágio a que lá assisti, (...) (28: 36)

(7) Com effeito, apezar da estreiteza de tempo, não só se fundou um Seminário e se povoou de meninos que OS NOSSOS PADRES criam e instruem em virtudes e lettras, com o máximo de cuidado (...) (32:86)

(8) Aí o pessoal pegou e resolveu entrar na água, né? O barco tava parado. TODO MUNDO pulou na água. E ... aí aquela festa, um chama o outro. (13-13: 433)

(9) E esses tempo atrás casou UM PRIMO NOSSO, e ... todo mundo foi contra. Piazão assim de uns dezenove anos. (16-16: 51)

\footnotetext{
3 É importante ressaltar que os verbos tratados por Berlinck (1988) como intransitivos existenciais são considerados, pela abordagem gerativista, verbos inacusativos existenciais. Além disso, os verbos intransitivos não existenciais são, em sua maioria, casos de verbos inacusativos não existenciais.

4 A numeração que acompanha os exemplos, segundo Berlinck (1988, p. 66), “corresponde ao número da entrevista e do informante e à linha em que a sentença se encontra na transcrição ou o número de ocorrências nas cartas".
} 
(10) Ultimamente ocorreu UM NOVO INCIDENTE entre os Ferreiras, proprietários do trapiche da Saúde, e o guarda-mor da Alfândega. (23: 56)

Os resultados de Berlinck são corroborados por Coelho (2006), a partir da descrição e análise da variação da ordem do sujeito em peças de teatro de 1859 a 1992, conforme pode ser observado na Tabela 2.2, com relação aos índices aferidos de VS.

\begin{tabular}{|c|c|c|}
\hline Cruzamento entre século e natureza do verbo & $\begin{array}{l}\text { Século XIX } \\
(1859,1868,1881)\end{array}$ & $\begin{array}{l}\text { Século XX } \\
(1980,1992)\end{array}$ \\
\hline Verbo inacusativo não existencial ${ }^{5}$ & $38 \%$ & $27 \%$ \\
\hline Verbo de ligação (ou cópula) & $11 \%$ & $9 \%$ \\
\hline Verbo intransitivo & $9 \%$ & $0 \%$ \\
\hline Verbo transitivo direto & $6 \%$ & $2 \%$ \\
\hline Verbo transitivo indireto & $11 \%$ & $1 \%$ \\
\hline Verbo transitivo direto e indireto (ou bitransitivo) & $19 \%$ & $2 \%$ \\
\hline Total & $15 \%$ & $8 \%$ \\
\hline
\end{tabular}

Tabela 2.2 - Percentuais de VS(0), segundo a correlação entre as variáveis século e natureza do verbo (adaptada de (oelho, 2006).

Exemplos de peças de teatro escritas por catarinenses no século XIX, retirados de Coelho e Martins (2012, p. 13, 16, 17), ilustram casos de ordem variável do sujeito em diferentes contextos sintáticos.

(11) mas nisto mesmo venceu-me O DIABO DO CHICO HYPPOLITO [Brinquedos de cupido (1898) de Antero Reis Dutra (1855-1911)]

(12) Não. Já jantei. Além d'isso allivem A POSTERIDADE DOS PALITOS. [Brinquedos de cupido (1898) de Antero Reis Dutra (1855-1911)]

(13) Diz-me uma cousa, TURIBIA; como é que ESTE MENINO sahio assim ruivo, sendo eu tão moreno? / Turibia - Não posso te explicar! [Os ciúmes do capitão (1880) de Arthur C. do Livramento (1853-1897)]

Como pode ser constatado na Tabela 2.2, a queda de VS - na passagem do século XIX para o século XX - está relacionada, principalmente, à transitividade do verbo das construções. Essa variável foi controlada nos trabalhos de Berlinck

5 Coelho (2006) deixou os verbos inacusativos existenciais de fora da rodada estatística por terem se mostrado, na amostra investigada, verbos categoricamente de ordem VS. 
(1988; 1989; 1995) e de Coelho (2000; 2006), configurando-se como um dos principais condicionantes de VS. Enquanto o século XIX apresenta padrões distintos dessa ordem, em contextos com verbos transitivos, intransitivos, cópulas e inacusativos, no final do século XX é em contextos com verbos inacusativos que (ainda) temos uma margem considerável de VS (27\%). Esses resultados indicam que VS, no final do século XX, é preferencialmente uma construção inacusativa. Tais resultados vêm ressaltar o que Kato e Tarallo (1988) e Kato (2000), entre outros, já prediziam: que a ordem VS no PB contemporâneo é restrita a ambientes de monoargumentos, ocorrendo, sobretudo, em construções inacusativas.

Estudos mais recentes (cf. KATO et al., 2006; COELHO; MARTINS, 2009; 2012; COELHO; BERLINCK, 2012; BERLINCK, COELHO, no prelo) observaram que há diferentes padrões de inversão na escrita brasileira dos últimos séculos. Analisando um corpus de peças de teatro e de cartas pessoais do início do século XVIII ao fim do século XX, Kato et al. (2006) encontram evidências empíricas de três tipos de construções de VS: inversão germânica, românica e inacusativa, como ilustram os exemplos de (14) a (16), respectivamente (cf. KATO et al., 2006, p. 420-430).

(14) Emília, aos cinco anos estava EU órfão, e tua mãe, minha tia, foi nomeada por meu pai sua testamenteira e minha tutora (1845)

(15) Tocoù minha cunhada, como principal bem de fortuna e fonte de renda, A CONHECIDA FÁBRICA DE MEIAS DA RUA DE SANTA ENGRÁCIA (1896)

(16) Nesses planos estávamos, quando apareceu ESTE HOMEM, não sei donde (1845)

O padrão de inversão em (14) corresponde à inversão germânica, em que o sujeito (nominal ou pronominal) aparece imediatamente posposto ao verbo e é comum a presença de um constituinte argumental (complemento) ou não argumental (advérbio) em posição inicial, como na configuração XVS. Essas construções são encontradas principalmente na escrita dos séculos XVI, XVII e XVIII, mas são pouco usuais para falantes do PB do final do século XX, quando esse tipo de inversão se parece mais com uma construção formulaica (ou cristalizada).

No que diz respeito ao padrão de inversão ilustrado em (15), as autoras mostram que essas construções - conhecidas como inversão românica - estariam correlacionadas a casos em que o sujeito aparece na posição final da sentença, como em VOS, com uma nítida interpretação de foco, ou seja, quando uma informação nova é atribuída ao sujeito da sentença. Já o padrão ilustrado em (16) é o de uma construção VS inacusativa, ainda bem produtiva nos dias atuais. 
Kato et al. (2006) encontraram, na amostra analisada, poucas evidências dos padrões de inversão germânica e românica em textos do século XX, século no qual a inversão inacusativa foi majoritária, atestando o que os outros trabalhos já haviam mostrado.

Ao analisar contextos de inversão do sujeito em textos dos séculos XIX e XX, Coelho e Martins (2009), Coelho e Berlinck (2012) e Berlinck e Coelho (no prelo) também encontraram diferentes padrões de inversão em amostras do século XIX e um acentuado enrijecimento da ordem $\mathrm{SV}(\mathrm{O})$ no final do século XX, principalmente em construções transitivas. Os exemplos em (17), retirados de Coelho e Martins (2009), e os exemplos em (18), retirados de Coelho e Berlinck (2012), ilustram esses casos de inversão.

(17a) Desta vez não te fará ELLE companhia! [Os ciúmes do capitão (1880) de Arthur C. do Livramento (1853-1897)]

(17b) Grosseirão, grosseirão; ora a quem o dizes TU [Raimundo (1868) de Álvaro Augusto de Carvalho (1829-1865)]

(18a) Entretanto que estas e outras muitas cousas vê TODO MUNDO, os Senhores fiscaes não as enxergão; (...) [Correio Paulistano, São Paulo, 05 de julho de 1854/Sessão: A pedidos]

(18b) Não merecia resposta O BOLONIO: talvez não a entenda. [Carta de leitor, SP, 1854]

O fato de a escrita do século XIX passar para a escrita do final do século XX de inversão variável para ausência de inversão em construções transitivas parece evidência favorável à hipótese de que o padrão de ordem do sujeito no português escrito no Brasil deve ter se modificado.

Tomando como ponto de partida o fato de que as mudanças sintáticas relacionadas à ordem do sujeito são observadas a partir do século XIX, centramos a análise deste trabalho em dois conjuntos de cartas pessoais escritas por catarinenses, um da segunda metade do século XIX e outro da segunda metade de século XX. Esses dois conjuntos de cartas pessoais fizeram parte da amostra controlada por Berlinck e Coelho (no prelo) ${ }^{6}$ no trabalho sobre diferentes padrões

\footnotetext{
${ }^{6}$ As autoras apresentam um estudo sobre a ordem do sujeito em sentenças declarativas do português escrito em três regiões do Brasil (Sul, Sudeste e Nordeste), a partir de uma amostra de documentos (cartas de leitores, anúncios e cartas pessoais) dos séculos XIX e XX disponível nos corpora do Projeto Para a História do Português Brasileiro (PHPB). Desse conjunto de documentos, as cartas pessoais de Santa Catarina serão retomadas e reanalisadas neste trabalho.
} 
de inversão do sujeito (inversão germânica, românica e inacusativa) ${ }^{7}$ no $\mathrm{PB}$. Neste trabalho não levamos em conta esses diferentes padrões encontrados pelas autoras, mas contextos sintáticos e semânticos representados aqui pelas variáveis linguísticas: transitividade do verbo, posição do verbo e animacidade do sujeito, uma vez que tais restrições sintático-semânticas têm se mostrado, em trabalhos de Sociolinguística (cf. LIRA, 1986, BERLINCK, 1988; 1989; 1995; COELHO, 2000; 2006; ZILLES, 2000; SPANO, 2008; SANTOS, 2008, entre outros), como fatores condicionantes da ordem VS.

\subsubsection{O SUJEITO NULO}

Um dos trabalhos pioneiros sobre o parâmetro do sujeito nulo no PB foi o de Duarte (1993). A autora parte de postulados da teoria gerativa sobre as propriedades do parâmetro do sujeito nulo nas línguas [+pro-drop], como o italiano e o espanhol. Para analisar dados do português, a autora se fundamenta na Sociolinguística Variacionista, que permite controlar os contextos linguísticos e extralinguísticos que poderiam favorecer ou restringir a implementação do sujeito pronominal expresso no sistema linguístico do PB. Nessa discussão são controlados os contextos de sujeito nulo que cedem terreno ao pronome expresso e os fatores que condicionam essa variação.

A hipótese da autora é de que a redução do paradigma verbal, com a inserção dos pronomes você e a gente no quadro pronominal, em competição com os pronomes tu e nós, respectivamente, motivaria a perda do sujeito nulo. Seus principais resultados, com base em uma amostra de peças teatrais escritas no Rio de Janeiro ao longo dos séculos XIX e XX, podem ser visualizados na Tabela 2.3.

\begin{tabular}{|l|l|l|l|l|l|l|l|}
\hline Pessoa do discurso & \multicolumn{2}{|l}{ Período das peças de teatro } \\
\cline { 2 - 8 } & $\mathbf{1 8 4 5}$ & $\mathbf{1 8 8 2 - 3}$ & $\mathbf{1 9 1 8}$ & $\mathbf{1 9 3 7 - 8}$ & $\mathbf{1 9 5 5}$ & $\mathbf{1 9 7 5 - 8 6}$ & $\mathbf{1 9 9 0 - 9 2}$ \\
\hline $\mathbf{1}^{\text {R. Pessoa }}$ & $31 \%$ & $22 \%$ & $17 \%$ & $39 \%$ & $44 \%$ & $68 \%$ & $82 \%$ \\
\hline $2^{\text {n. }}$ Pessoa & $7 \%$ & $21 \%$ & $31 \%$ & $75 \%$ & $79 \%$ & $80 \%$ & $78 \%$ \\
\hline $3^{\text {n. Pessoa }}$ & $17 \%$ & $35 \%$ & $34 \%$ & $28 \%$ & $41 \%$ & $48 \%$ & $45 \%$ \\
\hline
\end{tabular}

Tabela 2.3 - Trajetória de sujeito expresso nas três pessoas do discurso ao longo do tempo (adaptada de Duarte, 1993, p. 117; Duarte et al., 2012, p. 22).

\footnotetext{
7 Vale ressaltar que, além de Berlinck e Coelho (no prelo), os padrões de inversão do sujeito já foram investigados também por Kato et al. (2006); Coelho e Martins (2009); Coelho e Berlinck (2012), entre outros. Maiores informações podem ser conferidas nesses trabalhos.
} 
Como podemos observar, há um aumento do sujeito expresso nas duas primeiras pessoas do discurso e uma estabilidade do sujeito nulo na terceira pessoa. Segundo os resultados, observa-se que as mudanças atestadas na primeira pessoa aparecem preferencialmente nos dois últimos períodos (1975 e 1992), com índices de $68 \%$ e $82 \%$, e coincidem com a entrada do pronome a gente, combinado com a forma verbal não distintiva (morfema zero), concorrendo com o pronome nós, combinado com a forma verbal com desinência distintiva (-mos).

Com relação à segunda pessoa, os resultados mostram um aumento expressivo do sujeito preenchido já a partir do quarto período de tempo, momento em que se observa a entrada do pronome você e, posteriormente, uma neutralização entre os pronomes você e tu combinados a formas verbais com desinência zero e sem distinção de tratamento de cortesia, como exemplificado de (19) a (20) (cf. DUARTE et al., 2012, p. 23-24). Já a terceira pessoa revela uma mudança mais lenta, com $17 \%$ de sujeitos nulos na primeira sincronia e $45 \%$ na última (cf. exemplo (21)).

(19) Ambrósio: Quando Ø te vi pela primeira vez, Ø não sabia que Ø eras viúva e rica. Ø Amei-te por simpatia. [O noviço, Martins Pena, 1845]

(20a) Margareth: Tu parece que gosta. Por falar nisso, como é que tutá coçando pé com o braço desse jeito? [No coração do Brasil, Miguel Falabella, 1992]

(20b) Margareth: Você não entende meu coração porque você tá sempre olhando pro céu e procurando chuva. [No coração do Brasil, Miguel Falabella, 1992]

Os percentuais permitem relacionar a perda de propriedades do parâmetro do sujeito nulo com a simplificação do quadro pronominal. Entretanto, a preferência pelo preenchimento do sujeito pronominal, nas três pessoas gramaticais, mesmo naquelas em que a flexão poderia garantir a interpretação do sujeito nulo, como na primeira pessoa do singular, por exemplo, mostra que não há uma implicação direta entre desinência distintiva e sujeito nulo e entre desinência não distintiva e sujeito expresso.

Ao revisitarem Duarte (1993), Duarte et al. (2012) mostram que os casos de sujeitos nulos identificados pela flexão do verbo (como $\varnothing$ vou, $\varnothing$ vais e $\varnothing$ vamos, por exemplo) no $\mathrm{PB}$ são residuais, competindo com sujeitos pronominais expressos, combinados com verbos sem desinência marcada, ou seja, com morfemas zero. Os autores, com base em uma amostra ampliada, refinaram a análise da terceira pessoa com a finalidade de verificar se o traço semântico do sujeito de terceira pessoa influenciaria na mudança paramétrica e observaram que sujeitos pronominais marcados com traços [+humano/+específico] apresentam 
aumento significativo de pronomes expressos, ao contrário dos sujeitos que têm os traços [-humano/-específico]. Os exemplos a seguir ilustram essa preferência de uso.

(21a) Maria Lúcia: Laurinha me ligou ontem, de Berlim. Ela está contente com a bolsa de estudo, e o dinheiro do apartamento ajudou muito. [A partilha, Miguel Falabella, 1990]

(21b) Ambrósio: Juquinha, gostas desta roupa? - Juca: Não. Ø Não me deixa correr, é preciso levantar assim... [O noviço, Martins Pena, 1845]

Nota-se, portanto, que os contextos de sujeito nulo aos poucos cedem lugar ao pronome expresso e os contextos internos que condicionam essa mudança estão ligados especialmente à implementação de novos pronomes pessoais no PB e a traços semânticos distintivos atrelados aos sujeitos pronominais de terceira pessoa. Tudo indica que a sintaxe do $\mathrm{PB}$ no que se refere ao parâmetro do sujeito nulo está passando por um período de transição de língua [+pro-drop] para língua [-pro-drop], sendo os casos de sujeitos nulos apenas resíduos de um paradigma que perdeu a sua riqueza funcional (DUARTE, 1993).

\subsection{DESCRIC̣ÃO E ANÁLISE DOS RESULTADOS}

Os estudos sobre preenchimento do sujeito e ordem em um período específico da escrita do PB, apresentados anteriormente, indicam dois tipos de mudança: queda da ordem VS e queda do sujeito nulo. Com o propósito de verificar a correlação desses dois fenômenos na escrita dos séculos XIX e XX, investigamos neste trabalho duas amostras de cartas pessoais organizadas e editadas pelo grupo do PHPB-SC, partindo do trabalho preliminar de Coelho et al. $(2015)^{8}$ : (i) vinte cartas escritas pelo poeta Cruz e Sousa à sua noiva Gavita, e pelos escritores Virgílio Várzea e Araújo Figueiredo, que faziam parte da Academia Catarinense de Letras, endereçadas a Cruz e Sousa, durante as décadas de 1880 e 1890 . Essas cartas foram coletadas junto ao Núcleo de Pesquisas em Informática, Literatura e Linguística (NUPILL) da UFSC; (ii) 41 cartas de amor e de amizade escritas na década de 1960 por quinze moças endereçadas a um mesmo jovem, Destinatário N, do Vale do Itajaí. São moças nascidas em Santa Catarina (moradoras da Grande Florianópolis, do Vale do Itajaí, do Planalto Serrano e da região Nordeste). 8 Essas cartas estão disponíveis no site dos corpora do PHPB Disponível em: <https://sites.google.com/site/
corporaphpb/home/corpora-manuscritos/manuscritos-santa-catarina>. Acesso em: 10 fev. 2016 . 
Após coletadas todas as sentenças com sujeito preenchido nas ordens SV e VS e todas as sentenças com sujeito pronominal nulo ou expresso das duas amostras utilizadas, passamos à categorização de todas as ocorrências, considerando as variáveis dependentes ordem do sujeito e forma de representação do sujeito pronominal. Essas duas variáveis foram descritas e analisadas a partir das seguintes variáveis independentes: (i) posição do verbo; (ii) material antes do verbo; (iii) transitividade do verbo; (iv) tipos de pronomes pessoais; (v) animacidade do sujeito; e (vi) época em que as cartas foram escritas. Levantamos todas as ocorrências de sujeitos pré-verbais e pós-verbais (sejam eles nominais ou pronominais) e todas as ocorrências de sujeito pronominal nulo e expresso na escrita das referidas cartas, no intuito de verificar se a trajetória da mudança da ordem do sujeito (cf. BERLINCK, 1988; 1989; 1995; COELHO, 2006; COELHO, MARTINS, 2009; COELHO, BERLINCK, 2012; BERLINCK, COELHO, no prelo) acompanhou: a) a trajetória de sujeito pronominal nulo para sujeito expresso; e b) a mudança nas formas de representação do paradigma pronominal.

Os exemplos a seguir ilustram alguns casos encontrados nas cartas dos séculos XIX e XX.

(22a) No entanto nostalgico Ø não vivo, nem desolado, porque ainda, segundo posso affirmar, Ø continuo a ter a alma cheia de affectos para com todos, principalmente para comtigo que, comquanto $\varnothing$ passassemos tanto tempo sem nos communicar por meio da escripta, Ø continúas a ser meu maior amigo, o mais altamente sincero e dedicado; porque vive junto de mim, habitando o mesmo castello de esperanças, A DOCE ELEITA DOS MEUS SONHOS, achada entre as mais procuradas. [Carta de Araujo Figueiredo para Cruz e Sousa - 5 de agosto de 1895]

(22b) Na battalha da vida, batalha essa contra horriveis desenganos, tem sido ELLA a minha unica espada de aço, forte como o tempo. [Carta de Araujo Figueiredo para Cruz e Sousa - 5 de agosto de 1895]

(23a) Destinatário N, Ø espliquei o assunto à minha mãe, ELA mandou que EU levasse ao teu conhecimento e pedisse uma opinião! Olhe "Uma opinião, será na vida uma arma, para extinguir uma barreira"! Dê a sua! Ø Ficarei contente. [Remetente $\mathrm{O}-1^{\circ}$ de setembro de 1969]

(23b) EU por minha parte, quero ser sincera, gosto muito de ti. Ø Falei com diversos rapazes mas $\varnothing$ nunca dediquei amor a nenhum como a ti dedico. EU julguei que havia encontrado a minha felicidade, mas, infelismente parece-me que esta felicidade não é para mim. É de outra não é? [Carta da Remetente A para jovem - 5 de abril de 1964]

Das amostras investigadas, foram categorizadas 611 ocorrências de sujeitos expressos para a análise da ordem do sujeito e 751 ocorrências de sujeitos 
pronominais para a análise do sujeito nulo e expresso. Os resultados da análise são apresentados e discutidos nas seções a seguir.

\subsubsection{A ORDEM DO SUJEITO E O SUJEITO PRONOMINAL}

Após categorização e análise das ocorrências de todas as sentenças declarativas com sujeito expresso (nominal e pronominal) nas ordens SV e VS, nos dois séculos, observamos que os índices não foram muito distintos. Conforme pode ser observado na Tabela 2.4, na sincronia da amostra Cruz e Sousa, constatamos 84\% de sujeito pré-verbal e $16 \%$ de sujeito pós-verbal e, nas cartas da amostra Vale, notamos índices muito parecidos: 87\% de SV e 13\% de VS. Quando observamos apenas os dados de sujeitos pronominais, a ordem SV se eleva nas duas sincronias, alcançando o índice de $95 \%$ no século XIX e de 97\% no século XX.

\begin{tabular}{|l|l|l|}
\hline Ordem do sujeito (nominal e pronominal) por século & SV & VS \\
\hline Século XIX & $133 / 158=84 \%$ & $25 / 158=16 \%$ \\
\hline Século XX & $392 / 453=87 \%$ & $61 / 453=13 \%$ \\
\hline Total & $\mathbf{5 2 5 / 6 1 1}=\mathbf{8 6} \%$ & $\mathbf{8 6 / 6 1 1}=\mathbf{1 4} \%$ \\
\hline
\end{tabular}

Tabela 2.4 - Percentual de variação da ordem do sujeito expresso (SV e VS) segundo o percurso do tempo.

\begin{tabular}{|l|l|l|}
\hline Ordem do sujeito pronominal por século & SV & VS \\
\hline Século XIX & $61 / 65=95 \%$ & $4 / 65=\mathbf{5} \%$ \\
\hline Século XX & $177 / 182=97 \%$ & $5 / 182=\mathbf{3} \%$ \\
\hline Total & $\mathbf{2 3 8 / 2 4 7}=\mathbf{9 7} \%$ & $\mathbf{9 / 2 4 7}=\mathbf{3} \%$ \\
\hline
\end{tabular}

Tabela 2.5 - Percentual de variação da ordem do sujeito pronominal expresso (SV e VS) segundo o percurso do tempo.

Apesar de aparentemente os índices de VS se mostrarem muito próximos nas duas sincronias analisadas (dentro da mesma casa decimal), é importante registrar que, na Tabela 2.4, a porcentagem de redução de VS referente aos índices de $16 \%$ a $13 \%$ é de $19 \%$ e que, na Tabela 2.5 , a porcentagem de redução de VS referente aos índices de $5 \%$ a $3 \%$ é de $40 \%$.

Além disso, se considerarmos a atuação da transitividade do verbo sobre a ordem do sujeito, nota-se que houve uma queda ainda mais acentuada de VS com verbos transitivos: de $8 \%$ no século XIX para $3 \%$ no século XX, conforme a Tabela 2.6, o que corresponde a uma porcentagem de redução de VS de $62 \%$ - percentual bastante expressivo. Com os demais verbos, à exceção dos intransitivos (por conta do número irrisório de ocorrências de VS - apenas um dado), a frequência 
de VS foi significativa nos dois séculos, em alguns casos mostrando inclusive um leve aumento percentual. Ressaltamos o elevado percentual de ordem VS com verbos inacusativos no século XX (32\% e $85 \%)$, o que reforça a tendência de a posposição se tornar cada vez mais restrita a esse tipo de verbo.

\begin{tabular}{|c|c|c|c|c|}
\hline \multirow[t]{2}{*}{ Transitividade do verbo } & \multicolumn{2}{|l|}{ Século XIX } & \multicolumn{2}{|l|}{ Século XX } \\
\hline & SV & VS & SV & VS \\
\hline Verbo inacusativo existencial & $1 / 3=33 \%$ & $2 / 3=67 \%$ & $2 / 14=15 \%$ & $12 / 14=85 \%$ \\
\hline Verbo inacusativo não existencial & $14 / 26=53 \%$ & $12 / 26=47 \%$ & $51 / 75=68 \%$ & $24 / 75=32 \%$ \\
\hline Verbo cópula & $33 / 38=86 \%$ & $5 / 38=14 \%$ & $88 / 106=83 \%$ & $18 / 106=17 \%$ \\
\hline Verbo intransitivo & $5 / 5=100 \%$ & $0 / 5=0 \%$ & $14 / 15=94 \%$ & $1 / 15=6 \%$ \\
\hline Verbo transitivo (direto, indireto, bitransitivo) & $79 / 86=92 \%$ & $7 / 86=8 \%$ & $189 / 195=97 \%$ & $6 / 195=3 \%$ \\
\hline
\end{tabular}

Tabela 2.6 - Percentual de variacão da ordem do sujeito (SV e VS) segundo a transitividade do verbo.

Quanto à posição do verbo na sentença, como podemos observar na Tabela 2.7, verbo em segunda posição é a construção sintática mais utilizada pelos informantes (cf. o número de ocorrências), seja no século XIX, seja no século XX. Esse resultado corrobora estudos anteriores (cf. COELHO; MARTINS, 2009; COELHO; BERLINCK, 2012; BERLINCK; COELHO, no prelo). Cruzando esse fator com a transitividade verbal, nota-se que verbos transitivos no século XIX apresentam prioritariamente a ordem XVS, com X realizado como advérbio ou como complemento (OVS), mas no século XX os três casos de VS aparecem com advérbio na posição pré-verbal (advVS).

\begin{tabular}{|l|l|l|l|l|}
\hline \multirow{2}{*}{ Posição do verbo na sentença } & \multicolumn{2}{l}{ Século XIX } & \multicolumn{2}{l|}{ Século XX } \\
\cline { 2 - 5 } & SV & VS & SV & VS \\
\hline Verbo em primeira posição & - & 11 & - & 24 \\
\hline Verbo em segunda posição & $98(95 \%)$ & $5(5 \%)$ & $191(89 \%)$ & $23(11 \%)$ \\
\hline Verbo em terceira ou quarta posição & $35(80 \%)$ & $9(20 \%)$ & $153(92)$ & $14(8 \%)$ \\
\hline
\end{tabular}

Tabela 2.7 - Percentual da posição do verbo na sentença segundo o percurso do tempo.

Considerando a variável forma de representação do sujeito, constatamos que a queda de VS com sujeito pronominal foi a mais relevante em nossa amostra, conforme os índices da Tabela 2.8 mostram: nos dados do século XIX, 95\% do sujeito pronominal na ordem SV e $5 \%$ na ordem VS; nos dados do século XX, $99 \%$ do sujeito pronominal na ordem SV e apenas $1 \%$ na ordem VS. Novamente podemos constatar uma porcentagem de redução de VS com sujeito pronominal bem expressiva, de $80 \%$. 


\begin{tabular}{|c|c|c|c|c|}
\hline \multirow[t]{2}{*}{ Forma de representação do sujeito } & \multicolumn{2}{|l|}{ Século XIX } & \multicolumn{2}{|l|}{ Século XX } \\
\hline & SV & VS & SV & VS \\
\hline Pronome & $61 / 64=95 \%$ & $3 / 64=5 \%$ & $227 / 230=99 \%$ & $3 / 230=1 \%$ \\
\hline Nome próprio & $14 / 16=88 \%$ & $2 / 16=12 \%$ & $1 / 2=50 \%$ & $1 / 2=50 \%$ \\
\hline Nome singular simples & $40 / 52=77 \%$ & $12 / 52=23 \%$ & $140 / 177=80 \%$ & $37 / 177=20 \%$ \\
\hline Nome composto & $18 / 25=72 \%$ & $7 / 25=28 \%$ & $26 / 44=59 \%$ & $18 / 44=41 \%$ \\
\hline
\end{tabular}

Tabela 2.8 - Percentual de variação da ordem do sujeito segundo a forma de representação do sujeito.

\begin{tabular}{|c|c|c|c|c|}
\hline \multirow[t]{2}{*}{ Animacidade do sujeito (terceira pessoa) } & \multicolumn{2}{|l|}{ Século XIX } & \multicolumn{2}{|l|}{ Século XX } \\
\hline & SV & VS & SV & VS \\
\hline SN [+ animado] & $36 / 43=83 \%$ & $7 / 43=17 \%$ & $45 / 51=88 \%$ & $6 / 51=12 \%$ \\
\hline SN [- animado] & $42 / 58=72 \%$ & $16 / 58=28 \%$ & $125 / 176=71 \%$ & $51 / 176=29 \%$ \\
\hline Total & $78 / 101=77 \%$ & $23 / 101=23 \%$ & $170 / 227=75 \%$ & $57 / 227=25 \%$ \\
\hline
\end{tabular}

Tabela 2.9 - Percentual de variação da ordem do sujeito segundo a animacidade do SN-sujeito.

Uma última variável controlada foi a animacidade do sujeito. Os percentuais expostos na Tabela 2.9 indicam queda de VS em contextos de SN [+animado] (de $17 \%$ a $12 \%$ ) e um pequeno aumento de VS em contextos de SN [-animado] (de $28 \%$ a $29 \%$ ). Esses resultados corroboram estudos anteriores de Berlinck (1988; 1989; 1995) e de Coelho $(2000 ; 2006)$, que apontam a animacidade do sujeito como um dos condicionadores de VS. Vale lembrar, no entanto, que a atuação dessa variável é indireta, uma vez que está condicionada ao verbo da construção sintática.

\subsubsection{A FORMA DE REPRESENTAÇÃO DO SUJEITO PRONOMINAL}

Após categorizadas e analisadas estatisticamente as 751 ocorrências de sujeitos pronominais nulos e expressos, constatamos um percurso de mudança bastante acentuado de sujeito nulo a sujeito expresso do século XIX ao século XX: de $81 \%$ de sujeitos nulos para $56 \%$ e de $19 \%$ de sujeitos expressos para $44 \%$ (cf. Tabela 2.10). Essa mudança de $81 \%$ para $56 \%$ significa uma porcentagem de $31 \%$ de redução do sujeito nulo - índice bastante expressivo. 


\begin{tabular}{|l|l|l|}
\hline Sujeito pronominal por século & NULO & EXPRESSO \\
\hline Século XIX & $267 / 332=81 \%$ & $65 / 332=19 \%$ \\
\hline Século XX & $237 / 419=56 \%$ & $182 / 419=44 \%$ \\
\hline Total & $\mathbf{5 0 4 / 7 5 1}=\mathbf{6 7} \%$ & $\mathbf{2 4 7 / 7 5 1}=\mathbf{3 3} \%$ \\
\hline
\end{tabular}

Tabela 2.10 - Percentual de sujeitos pronominais nulos e expressos.

Os exemplos a seguir ilustram alguns casos de sujeito nulo e expresso encontrados nos dois séculos.

(24) Adorada do meu coração, Ø não calculas a saudade que Ø sinto de ti, como eu desejava agora estar ao pé de ti, na alegria e na felicidade da tua presença, flor da minha vida, consolo do meu coração. [Cruz e Sousa, 1892]

(25) Ø tenho uma surprêsa para você, mais Ø acho que ainda e cedo para revelar-lhe. E se você for curioso não se preocupe, pois não é nada de importante. Segue um pequeno poema feito por mim, dedicado a você. [Remetente L, 1966]

(26) Ø Não podes imaginar a alegria que me causou o recebimento de teu bilhête. Em primeiro lugar $\varnothing$ quero agradecer-te pelo postal que Ø me enviaste. $\varnothing$ Não pensei que seria lembrada tão facilmente. [...] [Remetente B, 1966]

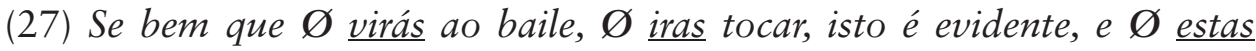
antecipadamente convidado. [Destinatário N], Ø espliquei o assunto à minha mãe, ela mandou que eu levasse ao teu conbecimento e pedisse uma opinião! [Remetente O, 1969]

Analisando separadamente cada uma das ocorrências de sujeito pronominal expresso na amostra do século XIX, notamos que, quando o sujeito pronominal é expresso, vem acompanhado de informação adicional de ênfase ou de contraste. Nesses casos, em geral, o pronome não poderia ser omitido. Os exemplos a seguir ilustram essa estratégia.

(28) Só tu és merecedôra de que eu te ame muito, como te amo, muito, muito, muito, e cada vez mais, com mais firmeza, sempre fiél, sempre teu escravo bom e agradecido, fazendo de ti, minha estrella, a esposa santa, adorada companheira dos meus dias. [Carta de Cruz e Sousa para Gavita - 14 de dezembro de 1892]

(29) Tu, Gavita, não me conbeces ainda bem, não sabes que amor eterno eu tenho no coração por ti, como eu adóro os teus olhos que me dão alegria, as tuas graças de mulher nova, de moça, carinhosa e amiga de sua boa mãe [Carta de Cruz e Sousa para Gavita - 31 de março de 1892] 
Verificando a ocorrência de sujeito nulo segundo a pessoa gramatical, conforme os índices apontados na Tabela 2.11, percebemos que os efeitos da mudança no paradigma pronominal e a consequente diminuição da frequência de sujeito nulo não atuam uniformemente sobre todas as pessoas gramaticais. $\mathrm{Na}$ primeira pessoa, verificamos uma frequência de $84 \%$ de sujeitos nulos na primeira sincronia, índice que cai para $49 \%$ no século XX. A segunda pessoa gramatical (tu) não apresenta mudança expressiva de um século para o outro, prevalecendo o uso do sujeito nulo: $81 \%$ no século XIX e $85 \%$ no século XX. De acordo com o estudo de Nunes de Souza e Coelho (2015), diferentemente do que atestam Duarte $(1993 ; 1995)$ e Duarte et al. (2012), o pronome tu ainda é muito recorrente na escrita catarinense do final do século XX, sendo utilizado para se dirigir aos familiares e amigos, marcando um maior grau de intimidade com os interlocutores. Com relação ao pronome de segunda pessoa você, na amostra do século XIX aqui analisada, aparece apenas uma vez na forma de segunda pessoa do plural (vocês), enquanto na amostra do século XX é usado com bastante frequência, aparecendo quase categoricamente expresso (96\%) e no singular. Em sua forma singular, o pronome você ora é usado como estratégia de formalidade, como ilustrado no trecho da carta da Remetente E (cf. exemplo (30)), ora compete com o pronome tu na posição de sujeito, aparecendo também em situação de maior intimidade (cf. exemplo (31)).

(30) Você também deve ter notado a diferença de tratamento que lhe dispensei. Vou explicar-lhe: considero o tratamento você muito impessoal por isso prefiro-o para cartas ou para pessoas totalmente desconhecidas. O mais costumo usar tu. Como Ø vêe, a gramática e eu não nos damos. [Amostra de Florianópolis, Carta da Remetente E - 7 de fevereiro de 1966]

(31) (...) tenho uma surprêsa para você, mais acho que ainda e cedo para revelar-lhe. E se você for curioso não se preocupe, pois não é nada de importante. Segue um pequeno poema feito por mim, dedicado a você. [Remetente L, 1966]

Já os altos percentuais de preenchimento na terceira pessoa - $75 \%$ no século XIX e 100\% no século XX - surpreendem, uma vez que esse é tradicionalmente um contexto de resistência ao avanço do sujeito expresso (cf. DUARTE, 1993; 1995). 


\begin{tabular}{|l|l|l|l|l|}
\hline \multirow{2}{*}{ Formas de realização do pronome } & Século XIX & \multicolumn{3}{l}{ Século XX } \\
\cline { 2 - 5 } & NULO & EXPRESSO & NULO & EXPRESSO \\
\hline Eu & $204 / 245=84 \%$ & $41 / 245=16 \%$ & $112 / 228=49 \%$ & $116 / 228=51 \%$ \\
\hline Tu & $55 / 68=81 \%$ & $13 / 68=19 \%$ & $61 / 72=85 \%$ & $11 / 72=15 \%$ \\
\hline Você(s) & $1 / 1=100 \%$ & $0 / 1=0 \%$ & $4 / 93=4 \%$ & $89 / 93=96 \%$ \\
\hline Ele / Ela & $3 / 12=25 \%$ & $9 / 12=75 \%$ & $0 / 9=0 \%$ & $9 / 9=100 \%$ \\
\hline
\end{tabular}

Tabela 2.11 - Percentual de sujeitos pronominais expressos e nulos considerando a forma de realização do pronome 9 .

Comparando os resultados dos dois séculos, podemos chegar a duas diferentes constatações. A preferência gradativa pelo preenchimento do sujeito pronominal, na primeira (eu), segunda (você) e terceira (ele/ela) pessoas gramaticais, mostra que no século XX não há uma implicação direta entre desinência distintiva e sujeito nulo e entre desinência não distintiva e sujeito expresso, diferentemente do que acontece no século XIX. Entretanto, com relação à segunda pessoa (tu) essa implicação existe. A grande maioria dos sujeitos tu, independentemente do século, aparecem nulos e com verbo na segunda pessoa do singular.

\begin{tabular}{|l|l|l|l|l|}
\hline Formas de realização do pronome de 3a pessoa & \multicolumn{2}{l|}{ Século XIX } & \multicolumn{2}{l|}{ Século XX } \\
\cline { 2 - 5 } & NULO & EXPRESSO & NULO & EXPRESSO \\
\hline + animado & $4 / 13=30 \%$ & $9 / 13=70 \%$ & $0 / 10=0 \%$ & $10 / 10=100 \%$ \\
\hline - animado & $3 / 4=75 \%$ & $1 / 4=25 \%$ & $0 / 1=0 \%$ & $1 / 1^{10}=100 \%$ \\
\hline
\end{tabular}

Tabela 2.12 - Percentual de sujeitos de $3^{\mathrm{a}}$ pessoa expressos e nulos, considerando a animacidade do antecedente ${ }^{10}$.

Quanto à animacidade do sujeito, como podemos ver na Tabela 2.12, os resultados mostram queda de sujeito nulo de terceira pessoa com antecedente [+animado] do século XIX para o XX (de 30\% para 0\%). Um antecedente [+animado] favorece, portanto, a implementação do pronome expresso. Esses resultados sobre o pronome de terceira pessoa com antecedente [+animado] corroboram os resultados mostrados por Duarte $(1993 ; 1995)$ e Duarte et al. (2012).

\footnotetext{
${ }^{9}$ Não foram considerados na análise os sujeitos pronominais plurais de primeira (nós) e terceira (eles/elas) pessoas, pela pequena quantidade de dados dessa natureza.

10 Não podemos afirmar nada sobre o antecedente [-animado] de terceira pessoa, por encontrar apenas um dado em nossa amostra do século XX.
} 


\subsection{CONSIDERAC̣ÕES FINAIS}

Como observamos na amostra analisada, não foi encontrada uma correlação ampla entre queda do sujeito nulo e queda da ordem do sujeito (de SV para VS). Entretanto, observa-se que a queda da ordem VS em construções com verbos transitivos, de $8 \%$ no século XIX para $3 \%$ no século XX, com uma porcentagem de redução de VS de $62 \%$, acompanha a queda de sujeitos nulos, que foi de $81 \%$ para $56 \%$ de um século para outro, o que indica uma porcentagem de $31 \%$ de redução do sujeito nulo. Esses resultados apontam uma trajetória de mudança de queda de VS com verbos transitivos e de queda de sujeito pronominal nulo em cartas pessoais de Santa Catarina, atestando nossa hipótese geral. Essa trajetória provavelmente está correlacionada à implementação de novos pronomes no paradigma pronominal do $\mathrm{PB}$ - como o pronome você - que se combinam com verbos sem marca distintiva de pessoa, conforme indicam os índices apresentados na Tabela 2.11.

Ressaltem-se também os resultados com relação à forma pronominal tu, que se mantém nulo nos dois séculos, enquanto as formas eu e ele/ela, com antecedente [+animado], apresentam mudança de pronome de nulo para pronome expresso. Além disso, é majoritariamente como sujeito pronominal expresso que você se implementa no português catarinense do século XX, competindo com o pronome tu nulo. Quando recortamos só o sujeito pronominal expresso, observa-se uma preferência pela ordem sujeito-verbo nas cartas do século XX, independentemente do tipo de verbo.

Não houve, entretanto, uma queda de sujeitos nulos tão acentuada, de uma sincronia para a outra, quanto a encontrada, por exemplo, nos trabalhos de Duarte $(1993 ; 1995)$. Talvez isso se deva ao fato de as peças de teatro (fonte dos dados de Duarte) procurarem reproduzir com mais fidelidade a situação real de fala, ao passo que as cartas pessoais, embora consistam em um ambiente de informalidade, são passíveis de revisão que venha a eliminar alguns traços do vernáculo dos remetentes.

A própria Duarte (1993) alerta para o fato de que os resultados com o gênero epistolar costumam apresentar diferenças, citando, por exemplo, o estudo de Oliveira (apud DUARTE, 1993), que encontrou, em cartas pessoais dos séculos XVIII, XIX e XX, elevados índices de sujeitos nulos de primeira e terceira pessoas ao longo de todos os períodos. Um exemplo que evidencia essa possibilidade de revisão que vai de encontro ao vernáculo é o da jovem que escreve pedindo desculpas por ter usado inadequadamente um pronome (cf. exemplo (30)). 


\subsection{REFERÊNCIAS}

BERLINCK, R. DE A. A ordem V SN no português do Brasil: sincronia e diacronia. Dissertação (Mestrado em Linguística) - Instituto de Estudos da Linguagem, Unicamp, Campinas, 1988.

A construção V SN no português do Brasil: uma visão diacrônica do fenômeno da ordem.In:TARALLO, Fernando (Org.).Fotografiassociolingüísticas. São Paulo: Pontes, 1989, p. 95-112.

. La position du sujet en portugais: etude diachronique des variétés brésilienne et européene. Tese (Doutorado em Linguística) - Faculteit Letteren, Katholieke Universiteit Leuven, Leuven, 1995.

BERLINCK, R. de A.; COELHO, I. L. A ordem do sujeito em construções declarativas na história do português brasileiro. In: História do Português Brasileiro. V. 3: Mudança gramatical do português brasileiro, Tomo 3: Mudança sintática na perspectiva formalista. No prelo.

CHOMSKY, N. Lectures on government and binding. Dordrecht: Foris, 1981.

COELHO, I. L. A ordem V DP em construções monoargumentais: uma restrição sintático-semântica. 2000, 245f. Tese (Doutorado em Linguística), Programa de Pós-graduação em Linguística, Universidade Federal de Santa Catarina, Florianópolis. 2000.

. Variação na sintaxe: estudo da ordem do sujeito no PB. In: RAMOS, J. M. (Org.). Estudos sociolinguísticos: quatro vértices do GT da ANPOLL. Belo Horizonte: Ed. UFMG, p. 84-99, 2006.

COELHO, I. L.; BERLINCK, R. DE A. Variação e mudança dos padrões de inversão do sujeito no português escrito em diferentes localidades no Brasil oitocentista. 2012. Trabalho apresentado no II Congresso Internacional de Linguística Histórica - USP, São Paulo, 2012.

COELHO, I. L.; MARTINS, M. A. A diacronia em construções XV na escrita catarinense. Fórum Linguístico, Florianópolis, v. 6, n. 1, p. 73-90, jan-jun, 2009. - Padrões de inversão do sujeito na escrita brasileira do século 19: evidências empíricas para a hipótese de competição de gramáticas. Alfa: Revista de Linguística, São Paulo, v. 56, n. 1, p. 11-28, 2012.

COELHO, I. L.; ZIBETTI, E. M. de; MELO, L. C. orrelação entre realização e ordem do sujeito: a trajetória da mudança no português catarinense. Trabalho apresentado no IX Congresso Internacional da ABRALIN - UFPA, Pará, 2015.

DUARTE, M. E. L. Do pronome nulo ao pronome pleno: a trajetória do sujeito no português do Brasil. In: ROBERTS, I.; KATO, M. A. (Org.). Português brasileiro: uma viagem diacrônica. Campinas: Editora da UNICAMP, 1993, p. 107-128. 
DUARTE, M. E. L.; MOURÃO, G. C.; SANTOS, H. M. Os sujeitos de $3^{\mathrm{a}}$ pessoa: revisitando Duarte 1993. In: DUARTE, M. E. L. (Org.). O sujeito em peças de teatro (1833-1992): estudos diacrônicos. São Paulo: Parábola, 2012. p. 21-44.

DUARTE, M. E. L. A perda do princípio "evite pronome" no português brasileiro. Tese (Doutorado em Linguística) - Instituto de Estudos da Linguagem, Unicamp, Campinas, 1995.

KATO, M. A. A restrição de monoargumentalidade da ordem VS no português do Brasil. Fórum Linguístico, Florianópolis, v. 2, n. 1, p. 97-127, 2000. The reanalysis of unaccusative constructions as existentials in Brazilian Portuguese. Revista do GEL, São Paulo, n. especial, p. 157-186, 2002.

KATO, M. A. et al. Português brasileiro no fim do século XIX e na virada do milênio. In: CARDOSO, S. A. M.; MOTA, J. A.; MATTOS E SILVA, R. V. (Org.). Quinhentos anos de história lingüística do Brasil. Salvador: Secretaria da Cultura e Turismo do Estado da Bahia, 2006. p. 413-438.

KATO, M. A.; TARALLO, F. Restrictive VS syntax in Brazilian Portuguese: its correlation with invisible clitics and visible subjects. Trabalho apresentado na Georgetown Round Table in Languages and Linguistics, Washington, 1988.

LABOV, W. Padrões sociolingüísticos. Tradução de Marcos Bagno, Marta Scherre e Caroline Cardoso. São Paulo: Parábola Editorial, 2008.

LIRA, S. de A. Subject postposition in Portuguese. Revista DELTA, São Paulo, v. 2, n. 1, p. 17-36, 1986.

NUNES DE SOUZA, C. M. et al. O preenchimento do sujeito pronominal em textos escritos de alunos adolescentes de Florianópolis. Working Papers em Linguística, Florianópolis, n. especial, p. 94-107, 2010.

NUNES DE SOUZA, C. M.; COELHO, I. L. Formas de tratamento em cartas pessoais de Santa Catarina. Trabalho apresentado no I Simpósio do Laborhistórico: História dos Pronomes de Tratamento no Português Brasileiro UFRJ, Rio de Janeiro, 2015.

RIBEIRO, I. M. DE O. A sintaxe da ordem do português arcaico: o efeito V2. Tese (Doutorado em Linguística) - Instituto de Estudos da Linguagem, Unicamp, Campinas, 1995.

. Sobre a perda da inversão do sujeito no português brasileiro. MATTOS E SILVA, R. V. (Org.). Para a história do português brasileiro. V. II, Tomo I - Primeiros estudos. São Paulo: Humanitas, 2001. p. 91-126.

RIZZI, L. The new comparative syntax: principies and parameters of universal grammar. Cahiers Ferdinand de Saussure, Genève, n. 43, p. 65-78, 1988.

SANTOS, D. DE R. A ordem VS/SV com verbos inacusativos: um estudo diacrônico. Dissertação (Mestrado em Linguística) - Faculdade de Letras, Universidade Federal do Rio de Janeiro, Rio de Janeiro, 2008. 
SANTOS, D. DE R.; SOARES DA SILVA, H. A ordem V-DP/DP-V com verbos inacusativos. In: DUARTE, M. E. L. (Org.). O sujeito em peças de teatro (18331992): estudos diacrônicos. São Paulo: Parábola, 2012. p. 121-142.

SPANO, M. A ordem verbo-sujeito no português brasileiro e europeu: um estudo sincrônico da escrita padrão. Tese (Doutorado em Linguística) - Faculdade de Letras, Universidade Federal do Rio de Janeiro, Rio de Janeiro, 2008.

TORRES MORAIS, M. A. C. R. Aspectos diacrônicos do movimento do verbo, estrutura da frase e caso nominativo no português do Brasil. In: ROBERTS, I.; KATO, M. A. (Org.). Português brasileiro: uma viagem diacrônica. Campinas: Editora Unicamp, 1993. p. 263-306.

WEINREICH, U.; LABOV, W.; HERZOG, M. Fundamentos empíricos para uma teoria da mudança linguística. Tradução de Marcos Bagno. São Paulo: Parábola, 2006.

ZILLES, A. M. S. A posposição do sujeito ao verbo no português falado no Rio Grande do Sul. Letras de Hoje, Porto Alegre, v. 35, n. 1, p. 75-96, 2000. 
